\title{
Especialización y rigor periodístico, antídotos contra los estigmas asociados a la enfermedad
}

\author{
Hernán Díaz \\ Fundación de Educación para la Salud (FUNDADEPS) \\ (Madrid, España)
}

\section{Palabra clave Resumen}

periodismo

enfermedad

estigmas

especialización

\begin{abstract}
En este artículo, el autor reflexiona sobre algunas tensiones y malas prácticas en los procesos de construcción de las noticias sobre temas relacionados con la salud y la enfermedad por parte de la prensa escrita, a partir de un análisis de la cobertura dada por las versiones digitales de los principales diarios españoles a la masacre de Newtown, Estados Unidos, donde en diciembre de 2012 un joven entró en una escuela y mató a 20 niños y 6 adultos. El autor señala en el artículo algunos de los errores manifiestos de la cobertura periodística del suceso, en el que la prensa relacionó la masacre con una supuesta enfermedad mental o trastorno del asesino alimentando ciertos estigmas sociales. En su reflexión, el autor señala dos tensiones en la práctica periodística que se hacen evidentes en casos como el estudiado: instanteneidad versus rigor periodístico y generalistas versus especializados. En ese sentido, propone que la especialización en comunicación y salud y la recuperación de las buenas prácticas periodísticas, entre ellas el contraste riguroso de las fuentes y la consulta a expertos, son los dos principales antídotos para garantizar una cobertura informativa que evite caer en prejuicios y representaciones sociales estigmatizantes.
\end{abstract}

\section{Cómo citar el artículo}

Díaz, H. (2013). Especialización y rigor periodístico, antídotos contra los estigmas asociados a la enfermedad. Revista de Comunicación y Salud, 3(2), pp. 33-38.

DOI: http://doi.org/10.35669/revistadecomunicacionysalud.2013.3(2).33-38 
Corría el 14 diciembre de 2012. La vida tranquila de la pequeña ciudad estadounidense de Newton, en el Estado de Connecticut, estallaba por los aires ante un suceso trágico. Un joven de 20 años, Adam Lanza, ingresaba armado a la escuela "Sandy Hook" y disparaba a los allí presentes, asesinando a 20 niños y 6 adultos, para suicidarse posteriormente. Más tarde se sabría que, antes de desatar esa masacre, también había asesinado a su madre en el hogar que compartían. Hasta aquí, un resumen de los hechos contrastados e irrefutables de un suceso que conmocionó a la sociedad americana, demasiado acostumbrada en los últimos tiempos a este tipo de acontecimientos.

En las horas posteriores, la noticia atravesó todas las fronteras y alcanzó la máxima relevancia en los informativos de todo el mundo. Y, como sucede muchas veces en este tipo de sucesos, en la construcción de la noticia se intentó buscar una explicación para un comportamiento inexplicable, razones para lo irracional, atribuyendo la causa del suceso a un trastorno de la conducta o enfermedad mental del asesino. Citaré a continuación una serie de ejemplos de esta asociación aparecida en las versiones digitales de los diarios españoles.

La misma tarde de la masacre, el diario El País daba una máxima cobertura al suceso en su versión digital y en un artículo titulado "Un asesino sin historia" destacaba que "los compañeros de instituto de Adam Lanza dicen que era un chaval "muy tímido, bastante retraído', y padecía un trastorno autista", una información que luego en el cuerpo del artículo se limitaba a comentarios de un amigo de un vecino que decía que había oído que el joven podría tener algún tipo de Trastorno del Espectro Autista (TEA) y, más concretamente, Asperger. Al parecer, según se justificó luego el Defensor del Lector de ese periódico, Tomás Delclós (2012), el error había ocurrido porque en un comienzo la información publicada era una traducción de un artículo del New York Times que incluía erróneamente esa afirmación.

Un cuarto de lo mismo sucedía en el diario El Mundo. En un artículo del día posterior titulado "Adam Lanza, un asesino múltiple de 20 años", el periódico repetía que "compañeros de instituto citados por The New York Times creen que sufría un trastorno de la personalidad o síndrome de Asperger (un trastorno del espectro autista)". Y para dar mayor pábulo a esa hipótesis, una semana después del suceso publicaba otro artículo en su versión digital bajo el título "Lanza podría haberse enterado de que su madre quería ingresarle en un psiquiátrico". Al mismo tiempo, en otra noticia se describía al asesino como "antisocial pero muy inteligente", un mito muy extendido en la sociedad en torno a las personas con Asperger.

Podríamos seguir detallando la forma en que los medios de comunicación españoles (y seguramente los de muchos otros lugares del mundo) construyeron esta noticia. Pero, al menos en los casos a los que hemos tenido acceso, las explicaciones sobre el móvil de este suceso se dirigían siempre en la misma dirección: los supuestos trastornos en el comportamiento o alguna enfermedad mental del asesino. 


\section{Reacciones frente a la estigmatización}

Es evidente que la construcción de la noticia generó una importante corriente crítica, que se manifestó rápidamente en los comentarios a esas noticias de los lectores de los periódicos digitales. En ese contexto, la Federación Asperger España (FAE) difundió un comunicado en el que calificaba como "lamentable" el "ejercicio periodístico basado en la difusión de datos no contrastados o directamente basados en rumores que lejos de informar pretenden generar morbo y audiencia especulando de forma irresponsable. Esta asociación causa-efecto y el tratamiento poco serio y sensacionalista que algunos medios de comunicación están dando al tema hacen un terrible e injusto daño a las personas que padecen este síndrome y a sus familia".

Como experto en temas de comunicación y salud y al mismo tiempo padre de un niño con autismo, yo personalmente critiqué la cobertura periodística de esta noticia en un artículo de opinión publicada en el Portal de la Fundación de Educación para la Salud (FUNDADEPS) y difundida en redes sociales (Díaz, 2012). En ese artículo rechazaba "la irresponsable estigmatización de las personas con TEA que ha hecho parte de la prensa española, entre ellos el principal diario de este país, a la hora de informar sobre la tragedia de Newtown", y exponía que "en lugar de intentar explicar este suceso con hechos contrastados e irrefutables, han preferido atravesar el camino de la especulación indocumentada. Una forma de informar desde el prejuicio y la ignorancia que desconoce algunos de los principios básicos del buen periodismo". Una práctica que, como señalé en aquel momento, "no solo ha carecido del contraste de las fuentes exigido al buen periodismo, sino que además ha ayudado a estigmatizar a un colectivo de personas que, por el propio trastorno que padecen, ya tienen dificultades para relacionarse e integrarse socialmente".

De la misma forma, en ese artículo formulaba algunas preguntas que suponían el principio de la reflexión que estoy intentando hacer ahora. En caso de confirmarse que el asesino tenía algún trastorno autista: ¿Podía afirmarse que era la causa principal o un dato relevante para explicar ese suceso? ¿Hay alguna investigación seria que concluya que las personas con algún tipo de TEA pueden convertirse en asesinos en serie solo por el hecho de padecer ese trastorno? ¿Hay estadísticas que, cuando menos, sugieran que son seres más peligrosos que el resto de los humanos?

En respuesta a las críticas plasmadas en mi artículo, el Defensor del Lector de El País, Tomás Delclós, respondía pocos días después en su blog que "las menciones iniciales al supuesto trastorno del joven fueron un error (The New York Times ha explicado que los investigadores manejaron esta hipótesis) y pueden efectivamente inducir, involuntariamente, una interpretación absolutamente equivocada sobre lo sucedido que el diario no ha establecido". La pregunta que cabría hacerse es si el hecho de citar a fuentes de prestigio, como sin duda lo es el $N Y T$, les exime de su obligación de contrastar la información y valorar si está debidamente documentada.

Precisamente para contraponer la posible interpretación errónea de esas primeras informaciones, el diario El País publicó un día después (el 15 de diciembre) un artículo de la psiquiatra Lola Morón, en el que echaba por tierra esa relación causa-efecto entre 
el supuesto trastorno y el comportamiento asesino. En un artículo, Morón destacaba que "existe una amplia bibliografía en estudios de investigación en psicología social que demuestran que cualquier ser humano, aparentemente adaptado, es capaz de llevar a cabo acciones de las que ni él ni las personas cercanas les considerarían jamás capaces". Y disparaba críticas en dos sentidos: a la sociedad, "porque la retracción social, la timidez o el aislamiento no convierten a nadie en un asesino, sin embargo necesitamos que nos hablen de enfermedad mental, en un intento de poner una barrera entre estos sujetos y nosotros, sabernos incapaces de cometer una barbaridad porque nos sabemos sanos"; y los medios de comunicación, especialmente a los estadounidenses, "por su empeño en buscar un diagnóstico psiquiátrico para un asesino que convivía con armas de fuego desde la infancia, y que para perpetrar el asesinato se vistió con ropas de combate. Tal vez los interrogantes tengan más que ver con la naturalidad con la que se vive el uso de armas que con la existencia o no de trastornos mentales".

\section{Reflexiones en torno a la práctica periodística}

Es evidente que la cobertura de este suceso fue manifiestamente mejorable en términos periodísticos. Pero no quiero quedarme en esa valoración superficial, si se quiere anecdótica, sino intentar hurgar en las razones que pudieron hacer que eso sucediera. $Y$ pretendo hacerlo en torno a algunas preguntas que nos ayuden a reflexionar:

- ¿Cómo están influyendo los cambios en los procesos de producción de las noticias provocados por las nuevas tecnologías de la información?

- ¿Estos cambios están poniendo en peligro el rigor informativo?

- ¿Cómo podrían evitarse este tipo de errores informativos, que desde los prejuicios y la ignorancia terminan alimentando los estigmas?

Es indiscutible que el desarrollo e implantación de las nuevas tecnologías de la información han cambiado radicalmente la práctica periodística. En ese contexto, me interesa llamar la atención sobre dos tensiones que, en mi opinión, están cambiando el ejercicio de esta profesión:

- Instantaneidad versus rigor informativo. Uno de los cambios más notables que estamos viviendo es que la información puede llegar al mismo tiempo en que se está produciendo la noticia a públicos de todo el mundo, en formatos diversos y a través de múltiples canales, incluidos nuevos medios masivos de comunicación como son las redes sociales. Esto, que en un sentido es algo positivo porque favorece el acceso a la información, puede convertirse en un boomerang para los profesionales del periodismo porque el tiempo se convierte en un elemento de presión que pone en riesgo su obligación de contrastar las fuentes y validar la información. La prensa escrita es, sin lugar a dudas, la más afectada por esta transformación en el escenario mediático, porque si antes un sus periodistas disponía de cierto tiempo para contrastar la información hasta la hora de cierre ahora solo tienen unos minutos para hacerlo porque lo que leeremos mañana en 
papel debe estar publicado cuanto antes en su versión digital.

- Generalistas versus especializados. Los cambios descritos anteriormente están provocando también cambios en el perfil de los periodistas demandados por los medios. Si antes se valoraba sobre todas las cosas su capacidad para disponer de fuentes fiables que le dieran rigor a la información, potenciando el conocimiento de los temas y la especialización, ahora mismo está ganando terreno una visión "instrumental" del periodista en la que se valora cada vez más su capacidad para procesar la información en diferentes formatos y medios. Un proceso que, a mi modo de ver, se sustenta en la conformación de conglomerados multimedia en el que la información se convierte en una mercancía y el periodista es un mero engranaje más en la cadena de producción. En ese contexto, no es extraño que se produzcan errores de bulto como los señalados en este artículo.

\section{Los antídotos frente a los prejuicios}

Decía el psicólogo americano Elliot Aronson que los prejuicios son "una actitud hostil o negativa hacia un grupo distinguible basada en las generalizaciones derivadas de información imperfecta o incompleta" (FEAFES; 2010, 1). Dicho de otro modo, la estigmatización social asociada a la enfermedad se basa en buena parte de los casos en la ignorancia.

Por tanto, si lo que buscamos es evitar que se repitan errores como los descritos en este artículo, una de las respuestas está claramente en la formación especializada en comunicación y salud. Nos referimos a una formación integral, que aborde los procesos de comunicación para la salud en su complejidad, en una perspectiva que considere los diversos ámbitos de actuación (sistema sanitario, comunidad, medios de comunicación, organizaciones de salud) y a los diferentes actores en sus marcos culturales y sociales. Una propuesta de este tipo es la que ofrecemos desde la Cátedra Extraordinaria de Comunicación y Salud de la Universidad Complutense de Madrid, a través del Magíster online en Comunicación y Salud, y existen también otras propuestas formativas enfocadas específicamente a la práctica periodística, como las impulsadas por la Asociación Nacional de Informadores de la Salud (ANIS).

Más allá de la necesaria especialización en comunicación y salud, se impone también una reflexión en torno a las buenas prácticas periodísticas en esta materia. En ese sentido, siguiendo los planteamientos de la "Guía internacional sobre salud mental para los medios de comunicación" editada por FEAFES $(2010 ; 11)$, para evitar la propagación de estigmas y garantizar la calidad de la información sobre salud que producen los periodistas deberían hacerse una serie de preguntas:

- ¿Es la condición o estado de salud de la persona relevante al hecho sobre el que se está informando?

- En caso de que sí lo sea ¿Se incluye en la información comentarios de fondo informados de un profesional de la asistencia sanitaria, una persona que padezca la enfermedad o una organización especializada? 
- ¿Son exactos los términos utilizados en la información, o causará el lenguaje alguna ofensa innecesaria?

- ¿Se ha incluido información de contacto con organizaciones de personas que puedan estar pasando por una situación similar?

Los medios de comunicación son una fuente importante de las representaciones sociales a través de las cuales construimos nuestra realidad, entre ellas las relacionadas con la salud y la enfermedad. La formación especializada en comunicación y salud y la recuperación de las buenas prácticas periodísticas son los dos antídotos para evitar que la estigmatización y los prejuicios pongan en peligro la integración plena de personas que, por su propio estado de salud, están en una situación de vulnerabilidad.

\section{Referencias}

Delclós, Tomás. (2012). Retrato de un asesino. Diario El País. Disponible en http:// blogs.elpais.com/defensor-del-lector/2012/12/retrato-de-un-asesino.html. Recuperado el 15 de junio de 2013.

Díaz, Hernán. (2012). El estigma de la tragedia. Fundación de Educación para la Salud (FUNDADEPS). Disponible en http://www.fundadeps.org/EpsOpiniones. asp?codopinion=71. Recuperado el 15 de junio de 2013

Federación Española de Agrupaciones de Familiares y Personas con Enfermedad Mental (FEAFES). (2010). Lexicon. Guía Internacional sobre salud mental para los medios de comunicación. Disponible en http://www.feafes.org/publicaciones/Lexicon. pdf. Recuperado el 15 de junio de 2013.

Morón, Lola. (2012). El riesgo de diagnosticar. Diario El País, Disponible en http:// internacional.elpais.com/internacional/2012/12/15/actualidad/1355599629_975246. html. Recuperado el 15 de junio de 2013. 